\title{
Zinc binding properties of human prostatic tissue, prostatic secretion and seminal fluid
}

\author{
J. P. Kavanagh \\ Department of Urology, University Hospital of South Manchester, Withington, \\ Manchester M20 8LR, U.K.
}

\begin{abstract}
Summary. When studied by gel filtration, zinc in prostatic cytosol $\left(10^{5} \mathrm{~g}, 1 \mathrm{~h}\right)$ was associated with high $(>80000)$, medium $(3000-80000)$ and low molecular weight $(<3000)$ molecules in approximately equal proportions. The molecules of high and medium $M_{r}$ were not secreted into the prostatic fluid where all the zinc was associated with molecules of low $\mathrm{M}_{\mathrm{r}}$ (probably citric acid). After ejaculation much of the zinc is redistributed and becomes bound to molecules of high and medium $\mathrm{M}_{\mathrm{r}}$ of vesicular origin.
\end{abstract}

\section{Introduction}

Zinc concentrations in normal human seminal plasma are high in comparison to those in other body fluids and tissues. This zinc is secreted predominantly by the prostate gland (Mann \& LutwakMann, 1981). While much attention has been paid to the levels of seminal or prostatic zinc associated with different fertility states or different prostate pathologies, few investigators have considered the zinc-binding properties of seminal fluid. Whether the zinc is free or protein bound could markedly affect its biological activity. Arver (1980) investigated the zinc-binding molecules in seminal plasma by gel filtration and reported that high, intermediate and low molecular weight molecules were present. A surprising observation was a correlation between zinc bound to high molecular weight proteins and fructose, suggesting a vesicular origin for this component. Experiments performed with split ejaculates have tended to confirm this conclusion and support the concept of a post-ejaculatory redistribution of zinc from molecules of low molecular weight to those of high and intermediate $M_{r}$ values (Arver, 1982a; Arver \& Eliasson, 1982).

In the present study the zinc-binding properties of 'pure' prostatic secretion, prostatic cytosol and seminal plasma were compared.

\section{Materials and Methods}

Expressed prostatic secretion was obtained by digital rectal massage from men with apparently normal prostates or benign prostatic hyperplasia (Kavanagh, Darby \& Costello, 1982). Semen samples were obtained from donors providing specimens for artificial insemination. Seminal plasma was prepared by low speed centrifugation. Prostatic cytosol was prepared from tissue from prostates showing benign hyperplasia obtained by resection or open surgery. This tissue was finely chopped, frozen in liquid $\mathbf{N}_{2}$ and disrupted in a Braun Melsungen Mikro-Dismembrator $(15 \mathrm{~mm}$ deflection for $15 \mathrm{sec}$ ). The powder was suspended in $10-20$ volumes of $0.05 \mathrm{M}-\mathrm{Tris}-\mathrm{HCl} \mathrm{pH} 7.5$ and 
centrifuged at $100000 \mathrm{~g}$ at $4^{\circ} \mathrm{C}$ for $1 \mathrm{~h}$. The supernatant was freeze-dried and re-suspended in 0.5-1 ml buffer.

Zinc concentrations were determined by atomic absorption spectroscopy (Kavanagh \& Darby, 1982). Fructose was determined by a resorcinol method (Polakoski $\&$ Zaneveld, 1977).

For column chromatography, up to $100 \mu \mathrm{l}$ of sample containing $10-80 \mu \mathrm{g}$ zinc were applied to a G-75 Sephadex column $(9 \times 150 \mathrm{~mm})$. Constant volume fractions of about $0.3 \mathrm{ml}$ (checked gravimetrically) were collected. The fractions were diluted to $3 \mathrm{ml}$ with $0 \cdot 1 \mathrm{M}$-nitric acid before zinc determination. Protein elution was monitored by the absorbance at $280 \mathrm{~nm}$.

\section{Results}

Purity of prostatic fluid. In a previous study (Kavanagh \& Darby, 1982) it was noted that the urea concentration of 69 samples of prostatic fluid was very similar to that of serum. This has now been confirmed in a series extended to 107 samples, of which only 15 would be classified as having above normal serum urea levels. Urinary contamination of expressed prostatic secretion is not therefore considered a significant problem. The fructose concentrations of a series of 57 prostatic fluid samples had a mean of $1.17 \mathrm{mM}$ and a median of $0.40 \mathrm{~mm}$. Taking $30 \mathrm{~mm}$ as an upper limit for normal seminal fructose (Mann \& Lutwak-Mann, 1981) then prostatic fluid samples having fructose concentrations higher than $1.5 \mathrm{~mm}(>5 \%$ of maximum seminal level) might be considered as contaminated with seminal vesicular secretion. On this basis 8 of the 57 samples tested were contaminated. Of the 5 prostatic fluid samples used in the gel filtration studies 2 formed part of this series of 57 . Their fructose concentrations were 0.7 and $1.2 \mathrm{~mm}$.

Gel filtration. Five samples of prostatic cytosol, expressed prostatic fluid and seminal plasma were chromatographed through G-57 Sephadex. A representative zinc elution profile for each sample type is shown in Text-fig. 1, in which the volumes I, II and III correspond to the high,

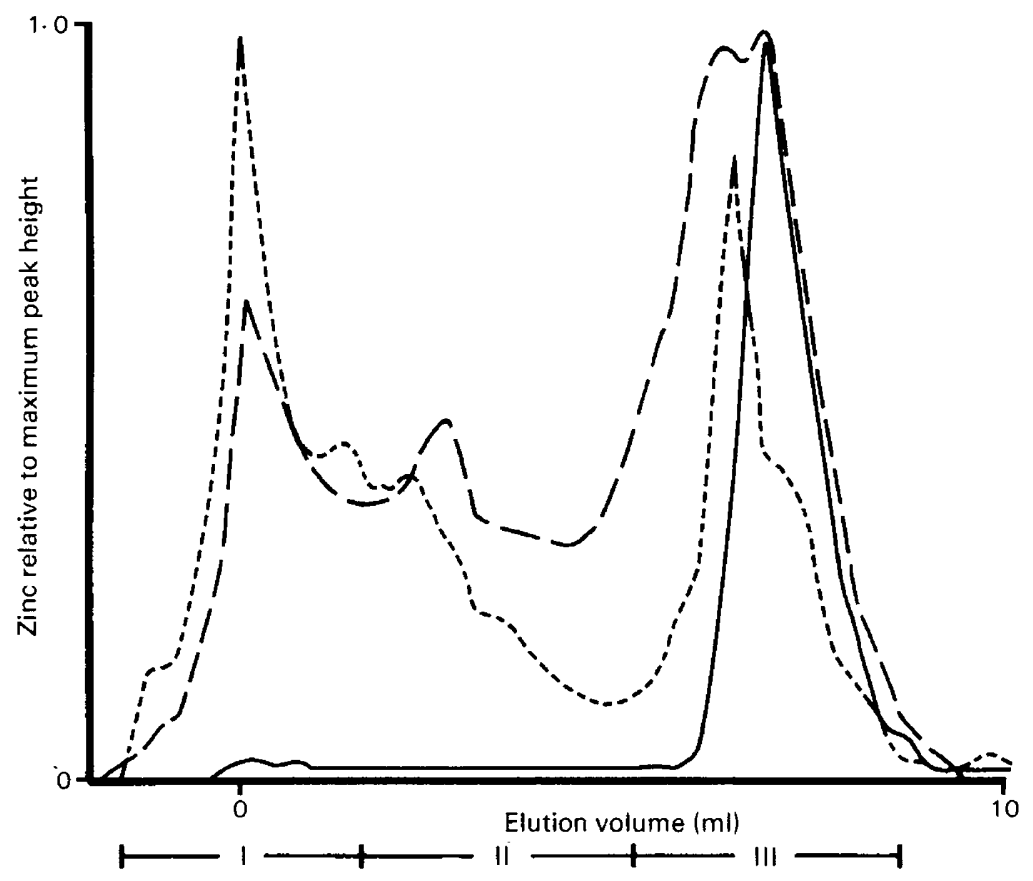

Text-fig. 1. Representative zinc elution from G-75 Sephadex for prostatic fluid (-), seminal fluid (--) and prostatic cytosol (....). 
intermediate and low molecular weight regions used by Arver $(1980)(<80000,3000-80000$ and $<3000$ respectively). The zinc in prostatic cytosol was distributed fairly evenly between the 3 types of molecules while that from expressed prostatic fluid entirely associated with the low $\mathbf{M}_{\mathbf{r}}$ components. In seminal plasma much of the zinc was bound to molecules of high and intermediate molecular weight (Table 1).

Table 1. Proportion of zinc (mean and range) associated with binding molecules of high, intermediate and low molecular weight (regions I, II and III, respectively, of Text-fig. 1)

\begin{tabular}{lccc}
\hline & \multicolumn{3}{c}{$\%$ of total zinc } \\
\cline { 2 - 4 } & Region I & Region II & Region III \\
\hline Prostatic cytosol & $39 \cdot 6$ & $24 \cdot 4$ & $35 \cdot 0$ \\
& $(29 \cdot 0-50 \cdot 1)$ & $(13 \cdot 3-28 \cdot 8)$ & $(24 \cdot 2-57 \cdot 5)$ \\
Prostatic fluid & $2 \cdot 5$ & $1 \cdot 4$ & $96 \cdot 1$ \\
& $(1 \cdot 1-3 \cdot 6)$ & $(0 \cdot 8-3 \cdot 1)$ & $(93 \cdot 3-98 \cdot 0)$ \\
Seminal fluid & $22 \cdot 5$ & $24 \cdot 9$ & $52 \cdot 6$ \\
& $(17 \cdot 4-26 \cdot 4)$ & $(10 \cdot 0-34 \cdot 6)$ & $(46 \cdot 0-72 \cdot 6)$ \\
\hline
\end{tabular}

Comparison of the seminal plasma and prostatic fluid results suggests a post-ejaculatory redistribution of zinc from low to higher molecular weight molecules, the extent of which appears to be related to the amount of vesicular fluid present in semen (estimated by fructose concentration) (Text-fig. 2).

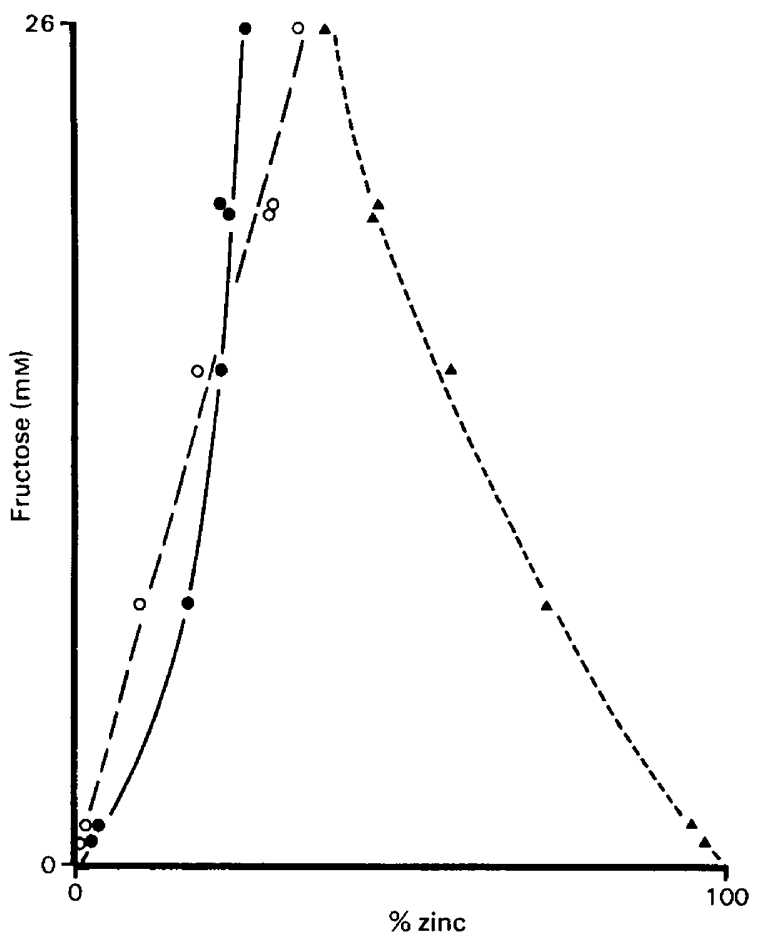

Text-fig. 2. Relationship between zinc from different molecular weight regions and fructose concentration from 2 prostatic and 5 seminal fluid samples ( $\bullet$, region I; O, region II; $\boldsymbol{\Delta}$, region III). 


\section{Discussion}

It is clear from these results that prostatic cytosol contains molecules of high and intermediate molecular weight which are not secreted into the prostatic acini. These are likely to be mainly epithelial in origin, where they must function intracellularly and may be concerned with accumulation of zinc or intracellular zinc transport. It has been observed that ${ }^{65} \mathrm{ZnCl}_{2}$, incubated with prostatic cytosol, eluted from G-200 Sephadex in the low molecular weight region (Reed \& Stitch, 1973). Further purification led to the isolation of a histidine-rich zinc-binding protein, whose molecular weight was estimated at 32000 (Heathcote \& Washington, 1973). Cells from a human prostatic adenocarcinoma cell line accumulate ${ }^{65} \mathrm{Zn}^{2+}$ which is associated with high and intermediate molecular weight molecules. The molecule of intermediate $M_{r}$ may be metallothionein (Giles \& Cousins, 1982). It has been suggested that the accumulation of prostatic zinc, via specific proteins (whose synthesis would be under androgenic control), could exert a feedback control on zinc uptake by inhibition of prostatic testosterone metabolism (Wallace \& Grant, 1975).

The almost complete absence of zinc-binding molecules in prostatic fluid is surprising in view of reports of seminal zinc-binding glycoproteins which may originate from the prostate (Herrmann, 1975; Clavert, Montagnon \& Brun, 1980). However both of these were electrophoretic studies and no attempt was made to quantify the proportion of free and bound prostatic fluid zinc. A low molecular weight zinc-containing antibacterial factor has been isolated from prostatic fluid and identified as mainly $\mathrm{ZnCl}_{2}$ (Fair, Couch \& Wehner, 1973). This preparation involved ion exchange chromatography which was likely to separate $\mathrm{Zn}^{2+}$ from any natural binding molecules. Arver (1982b) has presented convincing evidence that the zinc-binding molecule of low $\mathbf{M}_{\mathbf{r}}$ in seminal fluid is citrate. This is present in prostatic fluid in a 10 -fold molar excess over zinc (Kavanagh \& Darby, 1982) and both co-eluted from a G-15 Sephadex column. The major zinc-binding molecule of low $\mathrm{M}_{\mathrm{r}}$ in human milk is also thought to be citrate (Lonnerdal, Stanislowski \& Hurley, 1980; Martin, Licklider, Bushmiller \& Jacobs, 1981; Arver, 1982b).

Evidence presented here (Text-fig. 2) and elsewhere (Arver, 1980; Arver \& Eliasson, 1982) suggests that the zinc-binding molecules of high and intermediate molecular weight in seminal plasma are of vesicular origin. The intermediate $M_{r}$ components may be breakdown products of the high $\mathrm{M}_{\mathrm{r}}$ molecules which are glycoproteins (Arver \& Eliasson, 1982).

The significance of the post-ejaculatory redistribution of zinc is unclear but is suggestive of a process which requires activation or inhibition, the initiation of which needs to be synchronized to ejaculation. The obvious process is coagulation/liquefaction, and it has been suggested that the human coagulum is a glycoprotein matrix stabilized by divalent metal ions (Daunter, Hill, Hennessey \& Mackay, 1981). Other post-ejaculatory changes occur in seminal plasma. Well known are the hydrolysis of phosphorocholine by prostatic acid phosphatase and extensive proteolysis (Mann \& Lutwak-Mann, 1981). There is also a decrease in ionized calcium associated with an increasing $\mathrm{pH}$ and, although calcium is mainly excreted by the prostate, there is more ionized calcium in vesicular fractions than in prostatic fractions of split ejaculate semen (Arver \& Sjoberg, 1982).

These post-ejaculatory changes indicate that semen is a dynamic system that should not be considered simply as the sum of individual accessory fluids and spermatozoa.

\section{References}

Arver, S. (1980) Zinc and zinc ligands in human seminal plasma. I. Methodological aspects and normal findings. Int. J. Androl. 3, 629-642.

Arver, S. (1982a) Studies on zinc and calcium in human seminal plasma. Acta physiol. scand., Suppl. 507.

Arver, S. (1982b) Zinc and zinc ligands in human seminal plasma. III. The principal low molecular weight zinc ligand in prostatic secretion and seminal plasma. Acta physiol. scand. 116, 67-73.

Arver, S. \& Eliasson, R. (1982) Zinc and zinc ligands in human seminal plasma. II. Contribution by ligands of different origin to the zinc binding properties of human seminal plasma. Acta physiol. scand. 115, $217-224$. 
Arver, S. \& Sjoberg, H.E. (1982) Calcium fractions in seminal plasma and properties of human spermatozoa. Acta physiol. scand. 116, 159-165.

Clavert, A., Montagnon, D. \& Brun, B. (1980) Studies on the origin and nature of seminal proteins by cellulose acetate electrophoresis. Andrologia 12, 338-344.

Daunter, B., Hill, R., Hennessey, J. \& Mackay, E.V. (1981) Seminal plasma biochemistry. I. Preliminary report. A possible mechanism for the liquefaction of human seminal plasma and its relationship to spermatozoal motility. Andrologia 14, 131-141.

Fair, W.R., Couch, J. \& Wehner, N. (1973) The purification and assay of the prostatic antibacterial factor. Biochem. Med. 8, 329-339.

Giles, P.J. \& Cousins, R.J. (1982) Hormonal regulation of zinc metabolism in a human prostatic carcinoma cell line (PC-3). Cancer Res. 42, 2-7.

Heathcote, J.G. \& Washington, R.J. (1973) Analysis of the zinc binding protein derived from the human benign hypertrophic prostate. J. Endocr. 58, 421-423.

Herrmann, W.P. (1975) Demonstration of glycoproteins containing zinc in human seminal plasma. Andrologia 7, 329-339.

Kavanagh, J.P. \& Darby, C. (1982) The interrelationships between acid phosphatase, aminopeptidase, diamine oxidase, citric acid, $\beta$-glucuronidase, $\mathrm{pH}$ and zinc in human prostatic fluid. Int. J. Androl. 5, 503512.
Kavanagh, J.P., Darby, C. \& Costello, C.B. (1982) The response of seven prostatic fluid components to prostatic disease. Int. J. Androl. 5, 487-496.

Lonnerdal, B., Stanislowski, A.G. \& Hurley, L.S. (1980) Isolation of a low molecular weight zinc binding ligand from human milk. J. Inorg. Biochem. 12, 7178.

Mann, T. \& Lutwak-Mann, C. (1981) Male Reproductive Function and Semen. Springer Verlag, Berlin.

Martin, M.T., Licklider, K.F., Bushmiller, J.G. \& Jacobs, F.A. (1981) Detection of low molecular weight copper (II) and zinc (II) binding ligands in ultrafiltrated milks - the citrate connection. J. Inorg. Biochem. 15, 55-65.

Polakoski, K.L. \& Zaneveld, L.J.D. (1977) Biochemical examination of the human ejaculate. In Techniques of Human Andrology, pp. 265-286. Ed. E. S. E. Hafez. Elsevier/North Holland Biomedical Press, Amsterdam.

Reed, M.J. \& Stitch, S.R. (1973) The uptake of testosterone and zinc in vitro by the human benign hypertrophic prostate. J. Endocr. 58, 405-419.

Wallace, A.M. \& Grant, J.K. (1975) Effect of zinc on androgen metabolism in the human hyperplastic prostate. Biochem. Soc. Trans. 3, 540-542.

Received 25 October 1982 